CLINICAL STUDY

\title{
Polymorphisms at the regulatory regions of the CASR gene influence stone risk in primary hyperparathyroidism
}

Giuseppe Vezzoli, Alfredo Scillitani ${ }^{1}$, Sabrina Corbetta ${ }^{2}$, Annalisa Terranegra ${ }^{3}$, Elena Dogliotti ${ }^{3}$, Vito Guarnieri $^{4}$, Teresa Arcidiacono, Vera Paloschi, Francesco Rainone, Cristina Eller-Vainicher ${ }^{5}$, Loris Borghi ${ }^{6}$, Antonio Nouvenne ${ }^{6}$, Angela Guerra ${ }^{6}$, Tiziana Meschi ${ }^{6}$, Franca Allegri ${ }^{6}$, Daniele Cusi ${ }^{3}$, Anna Spada ${ }^{5}$, David E C Cole ${ }^{7}$, Geoffrey N Hendy ${ }^{8}$, Donatella Spotti and Laura Soldati ${ }^{3}$

Nephrology and Dialysis Unit, Postgraduate School of Nephrology, Vita Salute University, San Raffaele Scientific Institute, 20132 Milan, Italy, ${ }^{1}$ Endocrinology Unit, IRCCS 'Casa Sollievo della Sofferenza' Hospital, 71013 San Giovanni Rotondo, Foggia, Italy, ${ }^{2}$ Endocrinology and Diabetology Unit, Department of Medical-Surgical Sciences, Università degli Studi di Milano, Policlinico San Donato IRCCS, 20097 San Donato, Milan, Italy, ${ }^{3}$ Department of Medicine Surgery and Dentistry, Postgraduate School of Nephrology, Università degli Studi di Milano, 20142 Milan, Italy, ${ }^{4}$ Genetics Unit, IRCCS 'Casa Sollievo della Sofferenza' Hospital, 71013 San Giovanni Rotondo, Foggia, Italy, ${ }^{5}$ Endocrine Unit, Department of Medical Sciences, Fondazione Ospedale Maggiore Mangiagalli e Regina Elena IRCCS, Università degli Studi di Milano, 20122 Milan, Italy, ${ }^{6}$ Department of Clinical Sciences, University of Parma, 43100 Parma, Italy, ${ }^{7}$ Pathobiology, Medicine and Genetics, University of Toronto, Toronto, Ontario M5G 1L5, Canada and ${ }^{8}$ Department of Medicine, Physiology and Human Genetics, McGill University, Montreal, Quebec H3A 1A1, Canada

(Correspondence should be addressed to G Vezzoli who is now at Unità di Nefrologia e Dialisi, IRCCS Ospedale San Raffaele, Via Olgettina 60, 20132 Milano, Italy; Email: vezzoli.giuseppe@hsr.it)

\begin{abstract}
Background and objective: Single nucleotide polymorphisms (SNPs) of the calcium-sensing receptor (CASR) gene at the regulatory region were associated with idiopathic calcium nephrolithiasis. To confirm their association with nephrolithiasis, we tested patients with primary hyperparathyroidism (PHPT).

Design: A genotype-phenotype association study.

Methods: In all, 332 PHPT patients and 453 healthy controls were genotyped for the rs7652589 $(\mathrm{G}>\mathrm{A})$ and rs1501899 (G>A) SNPs sited in the noncoding regulatory region of the CASR gene. Allele, haplotype, and diplotype distribution were compared between PHPT patients and controls, and in stone forming and stone-free PHPT patients.

Results: The allele frequency at rs7652589 and rs1501899 SNPs was similar in PHPT patients and controls. The A minor alleles at these two SNPs were more frequent in stone forming $(n=157)$ than in stone-free $(n=175)$ PHPT patients (rs7652589: 36.9 vs $27.1 \%, P=0.007$; rs1501899: 37.1 vs $26.4 \%, P=0.003)$. Accordingly, homozygous or heterozygous PHPT patients for the AA haplotype ( $n=174$, AA/AA or AA/GG diplotype) had an increased stone risk (odds ratio $1.83,95 \%$ confidence interval 1.2-2.9, $P=0.008$ ). Furthermore, these PHPT patients had higher serum concentrations of ionized calcium and parathyroid hormone $(1.50 \pm 0.015 \mathrm{mmol} / \mathrm{l}$ and $183 \pm 12.2 \mathrm{pg} / \mathrm{ml})$ than patients with the GG/GG diplotype $(n=145,1.47 \pm 0.011 \mathrm{mmol} / \mathrm{l} \quad(P=0.04)$ and $150 \pm 11.4 \mathrm{pg} / \mathrm{ml}$ $(P=0.049))$. Using a logistic regression model, the increase in stone risk in PHPT patients was predicted by AA/AA or AA/GG diplotype, the highest tertile of serum ionized calcium values and the lowest tertile of age.

Conclusions: Polymorphisms located in the regulatory region of the CASR gene may increase susceptibility of the PHPT patients to kidney stone production.
\end{abstract}

European Journal of Endocrinology 164 421-427

\section{Introduction}

Parathyroid glands regulate parathyroid hormone (PTH) secretion through the calcium-sensing receptor (CASR), a G-protein-coupled receptor located in the plasma membrane of their chief cells and activated by the extracellular calcium. Binding of calcium ions with the CASR extracellular domain ensues in the inhibition of PTH secretion to maintain serum concentrations of calcium within the normal range (1). CASR expression in the cell membrane is controlled by two alternative promoters (P1 and P2), located before either exon 1A or exon 1B of the CASR gene. They encode the same CASR protein and their functional differences are still unknown (2-4).

Primary hyperparathyroidism (PHPT) is characterized by a PTH-stimulated increase in serum concentrations of calcium and an abnormally high parathyroid 
gland set point (5). The expression of CASR, as mRNA or protein, was found downregulated in parathyroid adenomas from PHPT patients, thus contributing to the parathyroid set point increase in these patients (6-8).

Kidney stones that are generally related to hypercalciuria are a common complication in PHPT patients (9). Nonconservative Arg990Gly polymorphism (SNP) of the CASR gene is associated with a specific phenotype in PHPT patients, characterized by kidney stones, lower serum concentrations of PTH, and higher urine calcium excretion $(10,11)$. This SNP is located in Exon 7 of the CASR gene coding for the intracellular and the transmembrane domains of the molecule $(12,13)$. Two other SNPs (rs7652589 and rs1501899) of the CASR gene, located in the 5'-flanking region and Intron 1 of the CASR gene (Fig. 1), are associated with calcium

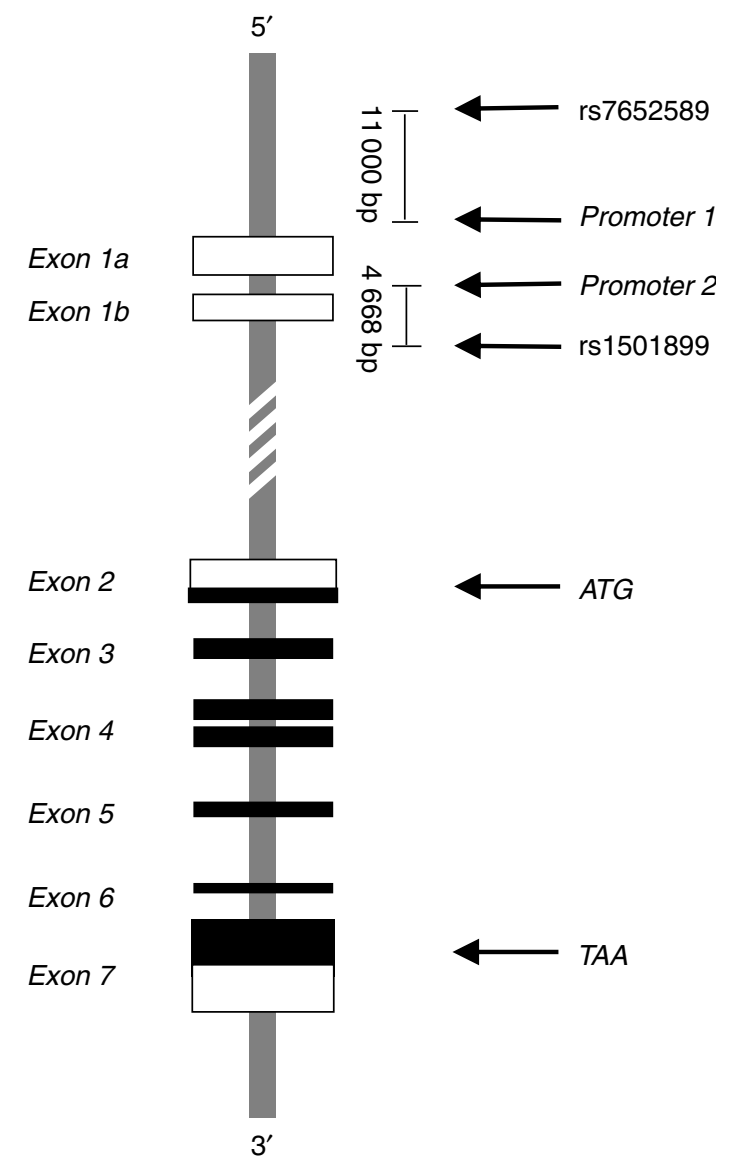

Figure 1 The CASR gene (in chromosome 3q13.3-21) spans $103 \mathrm{~kb}$. Exons are shown as either unfilled boxes (UTRs) or filled boxes (protein coding regions). Exons $1 \mathrm{a}$ and $1 \mathrm{~b}$ encode alternative 5'-UTRs. Exons 2-7 encode the CASR protein of 1078 amino acids. Exon 2 encodes part of the $5^{\prime}$-UTR, the translation start codon (ATG), and the $\mathrm{NH}_{2}$-terminal parst of the CASR. Exon 7 encodes the $\mathrm{COOH}$-terminal part of the CASR, the stop codon (TAA), and the $3^{\prime}$-UTR. rs7652589 (G>A, position 123371778) is located $\sim 11000$ bp upstream of $P 1$ in the $5^{\prime}$-flanking region of the $C A S R$ gene. rs 1501899 (G>A, position 123390018) is located $4668 \mathrm{bp}$ downstream of P2 within Intron 1 of the CASR gene $(4,14)$. kidney stones in idiopathic stone formers (12). These SNPs have not been functionally characterized, but their location in the CASR gene regulatory region including the gene promoters suggested that they might influence CASR expression. The bioinformatic analysis with the prediction tool MATCH 11.2 and the TRANSFAC 12.1 database on eukaryotic transcriptional regulation indicated that the variant alleles at rs7652589 and rs1501899 SNPs resulted in changes in transcription factors binding sites that downregulate CASR expression (14). This suggestion was consistent with the higher plasma levels of PTH found in idiopathic stone formers carrying these variant alleles (14). To confirm these findings in PHPT, the present work explored the distribution of the alleles at the rs7652589 and rs1501899 SNPs and their association with kidney stones in PHPT patients.

\section{Materials and methods}

\section{Patients and controls}

Three hundred and thirty-two patients with sporadic PHPT were recruited at the Endocrinology Units of the San Giovanni Rotondo Hospital and Fondazione Ospedale Maggiore in Milan from 2001 to 2006. Patients with hormonal and biochemical findings or a family history suggesting familial hypocalciuric hypercalcemia were excluded from this study. Patients with parathyroid carcinoma were also excluded. Their values of serum creatinine had to be $1.2 \mathrm{mg} / \mathrm{dl}$ or less.

Blood concentrations of total and ionized calcium, creatinine, and PTH were measured in all PHPT patients. Calcium/creatinine ratio was measured in spot urine collected in the morning after overnight fasting. Patients were routinely assessed for renal stones and were considered as stone formers if they had an ultrasound examination, urography, plain-film radiography positive for stones, or a positive history of urinary stone emission or surgical removal.

Controls $(n=453)$ included healthy volunteers who had a normal clinical examination on visiting the Policlinico Hospital in Parma as blood donors of the Fondazione Ospedale Maggiore in Milan, and blood donors of the Casa Sollievo della Sofferenza at San Giovanni Rotondo. The blood concentrations of the total calcium, creatinine, and PTH were measured in all healthy controls. The blood concentrations of ionized calcium were measured in the healthy individuals recruited at the Casa Sollievo della Sofferenza at San Giovanni Rotondo.

Individuals taking drugs or with diseases influencing bone metabolism other than PHPT were excluded from this study.

Total calcium, and creatinine were measured by standard colorimetric techniques. Ionized calcium was measured by specific electrode and serum intact PTH by IRMA or chemiluminescence method (both at Nichols 
Institute Diagnostics, San Juan Capistrano, CA, USA). Blood samples from each participant were stored at $-80{ }^{\circ} \mathrm{C}$ to genotype for CASR gene SNPs.

The study was approved by the Ethical Committees of the Casa Sollievo della Sofferenza Hospital in San Giovanni Rotondo, Fondazione Ospedale Maggiore Policlinico, Mangiagalli e Regina Elena, and San Raffaele Hospital in Milan. All participants provided informed consent to participate in the study.

\section{Genotyping}

All participants were genotyped for SNPs rs7652589 (G>A, position 123371778 , located in the $5^{\prime}$-flanking region of CASR gene) and rs1501899 (G>A, position 123390018 , located within Intron 1 of the CASR gene). rs7652589 is $\sim 11000 \mathrm{bp}$ upstream of $\mathrm{P} 1$ and rs1501899 is 4668 bp downstream of P2 (4) (Fig. 1). Genotyping was performed with the $5^{\prime}$ nuclease assay technology for allelic discrimination using fluorigenic probes in a specific Taqman SNP genotyping assay (Applied Biosystems, Foster City, CA, USA) as previously described (14). Amplification was performed in $8 \mu \mathrm{l}$ final volume with $20 \mathrm{ng}$ genomic DNA at the following conditions: $95^{\circ} \mathrm{C}$ for $20 \mathrm{~s}$, and 40 cycles each at $95^{\circ} \mathrm{C}$ for $3 \mathrm{~s}$, and $60{ }^{\circ} \mathrm{C}$ for $30 \mathrm{~s}$. SNP variation was assessed by means of the allelic discrimination assay employing the Applied Biosystems Software Package SDS 2.1. All genotyping ambiguity was resolved by checking raw fluorescence data and by repeating the genotyping.

Haplotypes, made by rs7652589 and rs1501899, were identified using PHASE (http://depts.washington.edu/ fphase/). The GG haplotype included the more recurrent alleles at these SNPs. AA haplotype included the rarer (minor) alleles at both SNPs. AG and GA haplotypes had the rarer allele at one of the two SNPs (15).

\section{Statistical analysis}

Distribution of CASR alleles, haplotypes, or diplotypes was analyzed by $\chi^{2}$ test or multinomial logistic regression. Relative risk of stone formation was estimated by calculating the odds ratio (OR) and 95\% confidence interval (95\% CI). Quantitative variables are reported as mean \pm s.e.m. Differences between means were tested by one-way ANOVA with Tukey's post hoc test to compare difference between the groups. Dependence of stones in the CASR gene polymorphisms was evaluated in a multinomial logistic regression model including CASR gene diplotypes (three groups), gender, and tertiles of age, serum ionized calcium, serum PTH, serum creatinine, and calcium excretion as independent variables. These statistical analyses were performed using the SPSS 11 statistical package (Chicago, IL, USA).

Linkage disequilibrium between SNPs over the CASR gene was analyzed using Haploview (http://www.broad. mit.edu/mpg/haploview). Evidence of linkage disequilibrium was considered as $D^{\prime}>0.7$ (16).

Statistical analysis was conducted at the $\alpha=0.05$ level and was two-tailed. For this $\alpha$ level and a difference in allele frequency at rs7652589 and rs1501899 of $10 \%$ we calculated that 309 participants had to be enrolled to have a statistical power of $80 \%$ (17).

\section{Results}

\section{CASR gene allele distribution in PHPT patients}

Table 1 shows the mean values of the variables measured in PHPT patients and controls and in PHPT patients with or without kidney stones. Patients with stones were younger and had higher serum calcium concentrations than patients without stones. The proportion of men was higher among PHPT stone formers.

Allele distribution at rs7652589 (G>A) and rs1501899 (G>A) SNPs respected the Hardy-Weinberg equilibrium in the whole population, in the group of PHPT patients, and in healthy individuals $\left(\chi^{2}\right.$ test; $\mathrm{DF}=2$, $P>0.86)$. Linkage disequilibrium was found between the rs7652589 and rs1501899 SNPs in PHPT patients $\left(D^{\prime}=0.95\right)$ and healthy controls $\left(D^{\prime}=0.93\right)$.

The frequency of the A variant alleles at rs7652589 and rs1501899 was not different in PHPT patients and healthy controls, whereas it was significantly higher in PHPT patients with stones than in those without stones (Table 2). Accordingly, the haplotype

Table 1 Biochemical and hormonal variables measured in PHPT patients, healthy controls, and in PHPT patients with or without kidney stones.

\begin{tabular}{lcccc}
\hline & Healthy controls & PHPT patients & $\begin{array}{c}\text { PHPT patients } \\
\text { without stones }\end{array}$ & $\begin{array}{c}\text { PHPT patients } \\
\text { with stones }\end{array}$ \\
\hline$n(\mathrm{M} / \mathrm{F})$ & $453(180 / 273)$ & $332(62 / 270)^{\dagger}$ & $157(22 / 135)$ & $175(40 / 135)^{\ddagger}$ \\
Age (years) & $43 \pm 0.6$ & $58 \pm 0.8^{\dagger}$ & $61 \pm 1.1$ & $56 \pm 1.0^{\ddagger}$ \\
Body weight $(\mathrm{kg})$ & $64 \pm 1.1$ & $70 \pm 0.9^{\dagger}$ & $68 \pm 1.3$ & $71 \pm 1.3$ \\
Serum ionized calcium $(\mathrm{mmol} / \mathrm{l})$ & $1.24 \pm 0.002(n=324)$ & $1.49 \pm 0.01^{\dagger}(n=264)$ & $1.45 \pm 0.009(n=129)$ & $1.52 \pm 0.015^{\star}(n=135)$ \\
Total serum calcium $(\mathrm{mmol} / \mathrm{l})$ & $2.32 \pm 0.005$ & $2.80 \pm 0.013^{\dagger}$ & $2.75 \pm 0.016$ & $2.84 \pm 0.020^{\star}$ \\
Serum PTH $(\mathrm{pg} / \mathrm{ml})$ & $42 \pm 0.74$ & $169 \pm 8.4^{\dagger}$ & $155 \pm 12.0$ & $181 \pm 11.8$ \\
Serum creatinine $(\mathrm{mg} / \mathrm{dl})$ & $0.82 \pm 0.007$ & $0.91 \pm 0.015^{\dagger}$ & $0.87 \pm 0.018$ & $0.95 \pm 0.023^{\ddagger}$ \\
Urine calcium $(\mu \mathrm{mol} / \mathrm{mmol}$ creatinine) & $\mathrm{ND}$ & $136 \pm 5.7$ & $126 \pm 7.4$ & $146 \pm 8.8$ \\
\hline
\end{tabular}

ND, not determined. ${ }^{\dagger} P=0.0001$ versus controls. ${ }^{\star} P=0.0001$ versus PHPT patients without stones. ${ }^{\ddagger} P<0.05$ versus PHPT patients without stones. 
Table 2 Frequency of the alleles and haplotypes at rs7652589 $(G>A)$ and rs1501899 (G>A) SNPs and frequency of the diplotypes including rs7652589 and rs1501899 in PHPT patients, healthy controls, and PHPT patients with or without kidney stones.

\begin{tabular}{|c|c|c|c|c|}
\hline \multirow[b]{2}{*}{$\begin{array}{l}\text { Allele or } \\
\text { haplotype } \\
\text { or diplotype }\end{array}$} & \multirow[b]{2}{*}{$\begin{array}{l}\text { Healthy } \\
\text { controls } \\
(n=453)\end{array}$} & \multicolumn{3}{|c|}{ PHPT patients } \\
\hline & & $\begin{array}{c}\text { Total } \\
(n=332)\end{array}$ & $\begin{array}{l}\text { Without } \\
\text { stones } \\
(n=157)\end{array}$ & $\begin{array}{c}\text { With } \\
\text { stones } \\
(n=175)\end{array}$ \\
\hline \multicolumn{5}{|l|}{ rs7652589 } \\
\hline A & 33.4 & 32.2 & 27.1 & $36.9^{*}$ \\
\hline \multirow{2}{*}{\multicolumn{5}{|c|}{ rs1501899 }} \\
\hline & & & & \\
\hline A & 31.5 & 32.1 & 26.4 & $37.1^{\dagger}$ \\
\hline G & 68.5 & 67.9 & 73.6 & 62.9 \\
\hline \multicolumn{5}{|c|}{ Haplotype including both SNPs } \\
\hline AA & 30.4 & 31.5 & 26.1 & $36.3^{\S}$ \\
\hline$A G$ and $G A$ & 4.3 & 2 & 2.2 & 1.7 \\
\hline GG & 65.3 & 66.6 & 71.7 & 62 \\
\hline
\end{tabular}

${ }^{*} \mathrm{OR} 1.6,95 \% \mathrm{Cl} 1.1-2.2, P=0.007 .{ }^{\dagger} \mathrm{OR} 1.6,95 \% \mathrm{Cl} 1.2-2.3, P=0.003$.

${ }^{\S} \mathrm{OR} 1.6,95 \% \mathrm{Cl} 1.2-2.2, P=0.006, \mathrm{GG}$ haplotype as the reference group.

AA including A allele at both the SNPs was more recurrent in PHPT patients with stones than in stonefree patients (Table 2).

\section{Diplotypes of the CASR gene in stone forming PHPT patients}

PHPT patients were distributed according to their diplotype including rs7652589 and rs1501899. GG/GG, GA/GG, AG/GG, AA/GG, and AA/AA diplotypes were detected in PHPT patients. Other diplotypes were not observed among PHPT patients. Taking patients with the GG/GG diplotype as the reference group, the frequency of stone formers was increased in PHPT patients carrying the AA/AA diplotype (OR 2.4, $95 \%$ CI 1.1-5.1, $P=0.029$ ) and in those carrying the AA/GG diplotype (OR 1.7, 95\% CI 1.1-2.8, P=0.024) (Fig. 2). No increased stone risk was found in patients carrying the AG/GG or GA/GG diplotype, considered as a unique group, but only 13 patients had these diplotypes (Fig. 2).

The stone risk was not different in the PHPT patients with the AA/AA or AA/GG diplotype carrying one or two copies of the AA haplotype (OR 1.4, 95\% CI $0.6-2.9, P=0.42)$. Considered together, these patients $(n=174)$ had a stone risk that was increased above 80.3\% (OR 1.83, 95\% CI 1.2-2.9, P=0.008; GG/GG patients as the reference group). Furthermore, PHPT patients carrying the AA/AA or AA/GG diplotype had higher serum concentrations of ionized calcium and PTH than patients with the GG/GG diplotype (Table 3).

A model of logistic regression was used to evaluate the variables predicting the stone risk in PHPT patients (Table 4). An increase in stone risk was associated with the AA/AA or AA/GG diplotype, the highest tertile of serum ionized calcium and the lowest tertile of age.

\section{Discussion}

In a previous study, we have observed an increased frequency of the minor alleles at the rs7652589 and rs1501899 SNPs of the CASR gene in idiopathic kidney stone formers (14). In the present study, we have genotyped PHPT patients for these two SNPs and found that their minor alleles were more frequent in patients with kidney stones. The distribution of alleles at these SNPs was similar in idiopathic and PHPT stone formers (14). Therefore, the rs7652589 and rs1501899 SNPs may be associated with idiopathic kidney stones and secondary forms of calcium kidney stones, like PHPT. However, these CASR gene SNPs were not associated with PHPT per se.

rs7652589 and rs1501899 SNPs are in linkage disequilibrium and are located in the first haplotype block of CASR gene (14). The haplotypes including the two minor alleles (AA) or the two more recurrent alleles (GG) at both the SNPs were predominant and the stone risk was more marked in homozygous and heterozygous patients for the AA haplotype (AA/AA and AA/GG diplotypes).

The rs7652589 SNP is situated $\sim 11000 \mathrm{bp}$ upstream of P1 and the rs1501899 SNP is $4668 \mathrm{bp}$ downstream of P2 (14). Even though they are located at some distance from the proximal promoters they have the potential to alter transcription of the CASR gene. A previous bioinformatic analysis suggested that the sequences of the minor alleles at rs7652589 and

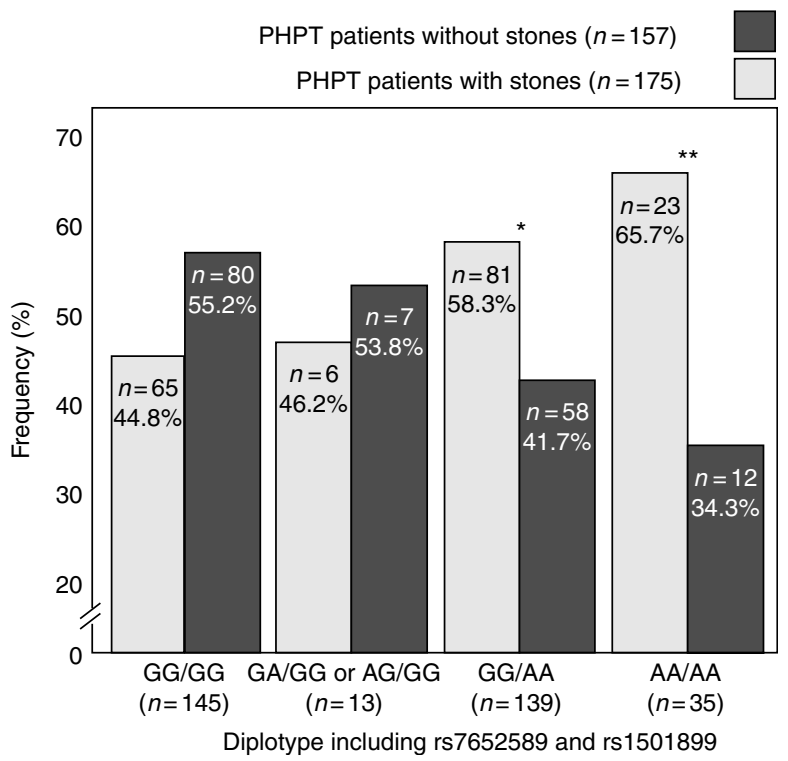

Figure 2 Distribution of the diplotypes including rs7652589 (G>A) and rs1501899 $(G>A)$ SNPs in PHPT with or without calcium kidney stones. We considered patients carrying $G G / G G, G A / G G$, or AG/GG (one group), GG/AA or AA/AA diplotype. No other diplotypes were found in PHPT patients. ${ }^{*} \mathrm{OR} 1.7,95 \% \mathrm{Cl} 1.1-2.8$, $P=0.024 ;{ }^{* *} \mathrm{OR} 2.4,95 \% \mathrm{Cl} 1.1-5.1, P=0.029$; patients with the $\mathrm{GG} / \mathrm{GG}$ diplotype as the reference group. 
Table 3 Quantitative variables in PHPT patients in relation to the diplotype including rs7652589 (G $>A)$ and rs 1501899 $(\mathrm{G}>\mathrm{A})$ SNPs.

\begin{tabular}{lccccc}
\hline & \multicolumn{5}{c}{ Diplotype including rs7652589 and rs1501899 } \\
\cline { 2 - 6 } & GG/GG & $\begin{array}{c}\text { AA/AA or } \\
\text { AA/GG }\end{array}$ & AA/AA & AA/GG & $\begin{array}{c}\text { GG/AG and } \\
\text { GG/GA }\end{array}$ \\
\hline$n$ & 145 & 174 & 35 & 139 & 13 \\
Age (years) & $58 \pm 1.2$ & $59 \pm 1.0$ & $58 \pm 1.9$ & $59 \pm 1.2$ & $58 \pm 3.8$ \\
Body weight $(\mathrm{kg})$ & $70 \pm 1.3$ & $70 \pm 1.3$ & $70 \pm 2.8$ & $70 \pm 1.5$ & $77 \pm 9.2$ \\
Serum ionized Ca (mmol/l) & $1.47 \pm 0.011$ & $1.50 \pm 0.015^{*}$ & $1.53 \pm 0.038$ & $1.50 \pm 0.016$ & $1.51 \pm 0.038$ \\
Total serum Ca (mmol/l) & $2.78 \pm 0.017$ & $2.81 \pm 0.020$ & $2.85 \pm 0.053$ & $2.81 \pm 0.022$ & $2.79 \pm 0.052$ \\
Serum PTH $(\mathrm{pg} / \mathrm{ml})$ & $0.91 \pm 0.023$ & $0.93 \pm 0.020$ & $0.97 \pm 0.043$ & $0.92 \pm 0.024$ & $0.74 \pm 0.048$ \\
Serum creat. $(\mathrm{mg} / \mathrm{dl})$ & $125 \pm 6.9$ & $146 \pm 8.9$ & $135 \pm 16.9$ & $144 \pm 10.7$ & $213 \pm 34.5$ \\
Urine Ca $(\mu \mathrm{mol} / \mathrm{mmol}$ creat.) & $150 \pm 11.4$ & $183 \pm 12.2^{\dagger}$ & $208 \pm 35.8$ & $177 \pm 12.3$ & $187 \pm 61.7$ \\
\hline
\end{tabular}

${ }^{\star} P=0.04,{ }^{\dagger} P=0.049$ versus $\mathrm{GG} / \mathrm{GG}$ patients; creat., creatinine.

rs1501899 could alter the binding sites of transcription factors that would normally be expected to upregulate the gene (14). Hence, transcription of the CASR gene in the presence of the minor alleles might be reduced leading to decreased CASR expression. Alternatively, the SNP within intron 1 might alter splicing of the pre-mRNA, or the SNPs might be in linkage disequilibrium with other SNPs in the CASR gene that could influence its activity.

A downregulation of the CASR expression agrees with higher serum concentrations of ionized calcium and PTH that we found in PHPT patients carrying variant alleles at both rs7652589 and rs1501899 SNPs. These findings had borderline significance, but we did not expect marked changes in serum calcium and PTH in PHPT patients in association with polymorphisms of a single gene, because these traits result from a complex network of biological influences. However, these findings may provide a functional indication and it is likely that CASR gene regulatory

Table 4 Results of logistic regression in PHPT patients considering stones as the dependent variable. Independent variables were the diplotype including rs7652589 and rs1501899, gender and tertiles of age, serum ionized calcium, serum parathyroid hormone, serum creatinine, and calcium excretion.

\begin{tabular}{llll}
\hline & $\begin{array}{c}\text { Odds } \\
\text { ratio }\end{array}$ & $\mathbf{9 5 \%} \mathbf{C l}$ & Significance \\
\hline $\begin{array}{l}\text { Diplotype } \\
\text { AA/AA or AA/GG diplotype }\end{array}$ & 1.9 & $1.1-3.5$ & 0.023 \\
AG/GG and GA/GG & 1 & $0.2-4.8$ & 0.97 \\
GG/GG (reference group) & 1 & & \\
$\begin{array}{l}\text { Serum ionized calcium } \\
\text { The highest tertile }\end{array}$ & 3.0 & $1.3-6.9$ & 0.009 \\
$\quad \begin{array}{l}\text { The middle tertile } \\
\text { The lowest tertile } \\
\quad \text { (reference group) }\end{array}$ & 1.3 & $0.7-2.5$ & 0.47 \\
$\begin{array}{l}\text { Age } \\
\text { The lowest tertile }\end{array}$ & 1 & & \\
$\quad \begin{array}{l}\text { The middle tertile } \\
\text { The highest tertile } \\
\text { (reference group) }\end{array}$ & 2.2 & $1.0-4.8$ & 0.044 \\
\hline
\end{tabular}

region SNPs may aggravate the decreased expression of CASR observed in parathyroid gland adenomas (6-8).

In the kidney, a CASR expression downregulation could contribute to stone production by increasing phosphate load to distal tubules and decreasing urine dilution and acidification capability of the collecting duct cells. These functional modifications were found in different experimental models in the presence of a reduced tubular CASR activity (18-20). The CASR effect on the urine acidification was shown to prevent tubular calcium phosphate precipitation in a hypercalciuric rat model (19). Instead, the efficacy of the CASR activity on water and phosphate reabsorption in protecting the kidney against calcium salt precipitation, although likely, has not been experimentally tested (18, 20). According to our hypothesis, a reduction in calcium excretion is expected in association with the rs7652589 and rs1501899 SNPs, because the CASR activation inhibits calcium reabsorption in the ascending limb and distal convoluted tubule $(8,21)$. However, hypercalciuria results from chronic hypercalcemia and the very high filtered calcium in PHPT. The consequent tubular calcium overload exceeds the tubular calcium reabsorption capability and may overwhelm the effect of the hypothesized CASR downregulation on the tubular calcium reabsorption $(8,22)$. This may explain why patients carrying minor alleles at the rs7652589 and rs1501899 SNPs did not have lower calcium excretion. On the contrary, the effect of the CASR downregulation on tubular phosphate, proton, and water handling, might amplify the calcium phosphate stone risk induced by hypercalciuria in PHPT patients (23).

In addition to the tubular effect, a protective activity of CASR against the Randall's plaque formation and calcium oxalate stones was hypothesized $(14,23)$. Findings in tissues different from kidney may support this hypothesis because a decreased CASR expression was observed in human calcified arteries and CASR activation may prevent calcium phosphate precipitation in arterial walls of uremic rats $(24,25)$. Therefore, the loss of CASR expression might expose the hypertonic 
interstitium of the kidney papillae to the risk of calcification as Randall's plaque (23).

In previous studies, Arg990Gly SNP was associated with stones and high calcium excretion in PHPT patients $(10,11)$. Our findings from different tests on transfected HEK-293 cells indicated that 990Gly might be an activating polymorphic allele $(14,26)$. Therefore, the stone risk in PHPT patients might be associated with SNPs having opposite effects on the CASR function: the activating nonconservative Arg990Gly SNP and downregulating rs7652589 and rs1501899 SNPs. This contradiction cannot be solved today and its resolution requires functional studies to test the effect of the variant alleles at rs7652589 and rs1501899 on the CASR gene transcription and their interaction with the Arg990Gly SNP. The transcriptional activity of CASR gene promoter from subjects with different genotypes could be directly tested in a luciferase system. Double transfected HEK-293 cells could then be prepared to investigate the interaction between the promoter activity and the Arg990Gly SNP. In addition, our findings need to be confirmed in other studies on wider PHPT populations.

In conclusion, our findings suggest that the rs7652589 and rs1501899 SNPs, located in the regulatory region of the CASR gene, are associated with a specific phenotype in the PHPT patients characterized by increased susceptibility to kidney stones and higher serum concentrations of ionized calcium and PTH. Since these SNPs do not cause an amino acid change and are located in the regulatory region of CASR gene, our findings are suggestive of a downregulation of the CASR expression in parathyroid and kidney cells. How this condition may determine the predisposition to stone remains unknown, but may be independent from hypercalciuria.

\section{Declaration of interest}

The authors declare that there is no conflict of interest that could be perceived as prejudicing the impartiality of the research reported.

\section{Funding}

This research was supported by grants from the Italian Ministry of University and Research (Principal Investigator L Soldati: FIRST 05, 06, 07, and PRIN 05) and San Raffaele Hospital.

\section{Acknowledgements}

We thank Alex Moncada for the linguistic advice.

\section{References}

1 Brown EM, Gamba G, Riccardi D, Lombardi M, Butters R, Kifor O, Sun A, Hedlger MA, Lytton J \& Hebert SC. Cloning and characterization of an extracellular Ca-sensing receptor from bovine parathyroid. Nature 1993366 575-580. (doi:10.1038/366575a0)
2 Canaff L \& Hendy GN. Calcium-sensing receptor gene transcription is up-regulated by the proinflammatory cytokine, interleukin- $1 \beta$. Journal of Biological Chemistry 2002277 30337-30350. (doi:10. 1074/jbc.M201804200)

3 Canaff L, Zhou X \& Hendy GN. The proinflammatory cytokine, interleukin-6, up-regulates calcium-sensing receptor gene transcription via Stat1/3 and Sp173. Journal of Biological Chemistry 2008283 13586-13600. (doi:10.1074/jbc.M708087200)

4 Canaff L \& Hendy GN. Human calcium sensing receptor gene: vitamin D response elements in promoters $\mathrm{P} 1$ and $\mathrm{P} 2$ confer transcriptional responsiveness to 1,25-dihydroxyvitamin D. Journal of Biological Chemistry $2005 \quad \mathbf{2 8 0}$ 14177-14188. (doi:10.1074/jbc.M408587200)

5 Silverberg SJ \& Bilezikian JP. The diagnosis and management of asymptomatic primary hyperparathyroidism. Nature Clinical Practice. Endocrinology and Metabolism 20062 494-503. (doi:10. 1038/ncpendmet0265)

6 Farnebo F, Enberg U, Grimelius L, Backdahl M, Schalling M, Larsson C \& Farnebo L. Tumor-specific decreased expression of calcium sensing receptor messenger ribonucleic acid in sporadic primary hyperparathyroidism. Journal of Clinical Endocrinology and Metabolism 199782 3481-3486. (doi:10. $1210 /$ jc. 82.10 .3481 )

7 Corbetta S, Mantovani G, Lania A, Borgato S, Vicentini L, Beretta E, Faglia G, Di Blasio AM \& Spada A. Calcium-sensing receptor expression and signaling in human parathyroid adenomas and primary hyperplasia. Clinical Endocrinology $2000 \mathbf{5 2}$ 339-348. (doi:10.1046/j.1365-2265.2000.00933.x)

8 Kifor O, Moore FD Jr, Wang P, Goldstein M, Vassilev P, Kifor I, Hebert SC \& Brown EM. Reduced immunostaining for the extracellular Ca21-sensing receptor in primary and uremic secondary hyperparathyroidism. Journal of Clinical Endocrinology and Metabolism 199681 1598-1606. (doi:10.1210/jc.81.4.1598)

9 Odvina CV, Sakhaee K, Heller HJ, Peterson RD, Poindexter JR, Padalino PK \& Pak CYC. Biochemical characterization of primary hyperparathyroidism with and without kidney stones. Urological Research 200735 123-128. (doi:10.1007/s00240-007-0096-2)

10 Corbetta S, Eller-Vainicher C, Filopanti M, Saeli P, Vezzoli G, Arcidiacono T, Loli P, Syren ML, Soldati L, Beck-Peccoz P \& Spada A. R990G polymorphism of the calcium-sensing receptor and renal calcium excretion in patients with primary hyperparathyroidism. European Journal of Endocrinology 2006155 687-692. (doi:10.1530/eje.1.02286)

11 Scillitani A, Guarnieri V, Battista C, De Geronimo S, Muscarella LA, Chiodini I, Cignarelli M, Minisola S, Bertoldo F, Francucci CM, Malavolta N, Piovesan A, Mascia ML, Muscarella S, Hendy GN, D'Agruma L \& Cole DEC. Primary hyperparathyroidism and the presence of kidney stones are associated with different haplotypes of the calcium-sensing receptor. Journal of Clinical Endocrinology and Metabolism 200692 277-283. (doi:10.1210/ jc.2006-0857)

12 Vezzoli G, Tanini A, Ferrucci L, Soldati L, Bianchin C, Franceschelli F, Malentacchi C, Porfirio B, Adamo D, Terranegra A, Falchetti A, Cusi D, Bianchi G \& Brandi ML. Influence of calcium-sensing receptor gene on urinary calcium excretion in stone-forming patients. Journal of the American Society of Nephrology $2002 \quad 13$ 2517-2523. (doi:10.1097/01.ASN. 0000030077.72157.D2)

13 Vezzoli G, Terranegra A, Arcidiacono T, Biasion R, Coviello D, Syren M, Paloschi V, Giannini S, Mignogna G, Rubinacci A, Ferraretto A, Cusi D, Bianchi G \& Soldati L. R990G polymorphism of calcium-sensing receptor does produce a gain-of-function and predispose to primary hypercalciuria. Kidney International 2007 71 1155-1162. (doi:10.1038/sj.ki.5002156)

14 Vezzoli G, Terranegra A, Arcidiacono T, Gambaro G, Milanesi L, Mosca E \& Soldati L. Calcium kidney stones are associated with a haplotype of the regulatory region of the calcium-sensing receptor gene regulatory region. Nephrology, Dialysis, Transplantation 2010 25 2245-2252. (doi:10.1093/ndt/gfp760) 
15 Scheet P \& Stephens M. A fast and flexible statistical model for large-scale population genotype data: applications to inferring missing genotypes and haplotypic phase. American Journal of Human Genetics 200678 629-644. (doi:10.1086/502802)

16 Barrett JC, Fry B, Maller J \& Daly MJ. Haploview: analysis and visualization of $\mathrm{LD}$ and haplotype maps. Bioinformatics 200521 263-265. (doi:10.1093/bioinformatics/bth457)

17 Gordon D, Finch SJ, Nothnagel M \& Ott J. Power and sample size calculations for case-control genetic association tests when errors are present: application to single nucleotide polymorphisms. Human Heredity 200254 22-33. (doi:10.1159/000066696)

$18 \mathrm{Ba} J$, Brown D \& Friedman PA. Calcium-sensing receptor regulation of PTH-inhibitable proximal tubule phosphate transport. American Journal of Physiology. Renal Physiology $2004 \mathbf{2 8 5}$ F1233-F1243. (doi:10.1152/ajprenal.00249.2003)

19 Renkema KY, Velic A, Dijkman HB, Verkaart S, van der Kemp AW, Nowik M, Timmermans K, Doucet A, Wagner CA, Bindels RJ \& Hoenderop JG. The calcium-sensing receptor promotes urinary acidification to prevent nephrolithiasis. Journal of the American Society of Nephrology 200920 1705-1713. (doi:10.1681/ASN. 2008111195)

20 Bustamante M, Hasler U, Leroy V, deSeigneux S, Dimitrov M, Mordasini D, Rousselot M, Martin PY \& Ferraille E. Calciumsensing receptor attenuates AVP-induced aquaporin-2 expression via a calmodulin-dependent mechanism. Journal of the American Society of Nephrology 200819 109-116. (doi:10.1681/ASN. 2007010092)

21 Motoyama HI \& Friedman PA. Calcium-sensing receptor regulation of PTH-dependent calcium absorption by mouse cortical ascending limbs. American Journal of Physiology. Renal Physiology 2002283 F399-F406. (doi:10.1152/ajprenal.00346.2001)
22 Silverberg SJ, Shane E, Jacobs TP, Siris ES, Gartenberg F, Seldin D, Clemens TL \& Bilezikian JP. Nephrolithiasis and bone involvement in primary hyperparathyroidism. American Journal of Medicine $1990 \mathbf{8 9}$ 327-334. (doi:10.1016/00029343(90)90346-F)

23 Evan AE, Lingeman JE, Coe FL, Bledsoe SB, Sommer AJ, Williams JC \& Worcester BM. Histopathology and surgical anatomy of patients with primary hyperparathyroidism and calcium phosphate stones. Kidney International 200874 223-229. (doi:10. 1038/ki.2008.161)

24 Alam M, Kirton JP, Wilkinson FL, Towers E, Sinha S, Rouhi M, Vizard TN, Sage AP, Martin D, Ward DT, Alexander MY, Riccardi D \& Canfield AE. Calcification is associated with loss of functional calcium sensing receptor in vascular smooth muscle cells. Cardiovascular Research 200981 2660-2668. (doi:10.1093/cvr/ cvn279)

25 Kawata T, Nagano N, Obi M, Miyata S, Koyama C, Kobayashi N, Wakita S \& Wada M. Cinacalcet suppresses calcification of the aorta and heart in uremic rats. Kidney International $2008 \mathbf{7 4}$ 1270-1277. (doi:10.1038/ki.2008.407)

26 Terranegra A, Ferraretto A, Dogliotti E, Scarpellini M, Corbetta S, Barbieri AM, Spada A, Arcidiacono T, Rainone F, Aloia A, Cusi D, Vezzoli G \& Soldati L. Calcimimetic R-568 effects on activity of R990G polymorphism of calcium-sensing receptor. Journal of Molecular Endocrinology 201045 245-256. (doi:10.1677JME10-0034)

Received 2 December 2010

Accepted 22 December 2010 